\title{
Eosinophilic Esophagitis in Patients with Refractory Gastro- esophageal Reflux Disease (GERD).
}

\author{
Hamed M. Soliman ${ }^{1}$, Rashed M. Hassan ${ }^{1}$, Mahmoud W. Emara ${ }^{2}$, \\ Mohammed E. Ali ${ }^{1}$, Tarik I. Zaher ${ }^{1}$, Sherif M. Galal ${ }^{1}$ \\ ${ }^{1}$ Endemic and Tropical Medicine Department, Faculty of Medicine, Zagazig University, Egypt \\ ${ }^{2}$ Pathology Department, Faculty of Medicine, Zagazig University, Egypt
}

Corresponding Author Tarik I Zaher

Email:tareqzaher@zu. edu.eg

Key words:Eosinophilic; esophagitis; refractory; GERD
Background and study aim : Eosinophilic esophagitis (EE) is defined as the presence of an abundant eosinophil infiltrate of the esophageal mucosa observed at biopsy. For some time, the existence of a pathophysiological relationship between GERD and EE has been speculated. The aim of this work is to estimate the frequency of eosinophilic esophagitis among patients with refractory reflux esophagitis.

Patients and Methods: We selected fifty patients diagnosed previously as refractory GERD(group I) . Another fifty patients corresponding in age and sex with group I with esophageal and extra-esophageal clinical symptoms suggestive of GERD were enrolled in this study as control (group II). All patients were subjected to upper GIT endoscopy (multiple biopsies were taken), 24 hrs esophageal $\mathrm{PH}$ monitoring, esophageal motility study, histopathology and immune -histochemistry of esophageal biopsies.

\section{INTRODUCTION}

Eosinophilic esophagitis (EE) is defined as the presence of an abundant eosinophil infiltrate of the esophageal mucosa observed at biopsy [1]. While it is true that there is still controversy about the number of eosinophils that must be observed per high power field (HPF) for the diagnostic standard of $\mathrm{EE}$, most authors have used a number equal or greater than 15 cells [2].

This disease was described in children and in adults [3]. An increased prevalence has been observed which may be
Results: Two patients with EE were found among patients with refractory GERD. Dysphagia, heart burn, and food impaction were the common presenting symptoms of patients with EE. Rings and furrow were the most common and significant endoscopic pictures in cases of EE. Eosinophils, microabces, basal zone hyperplasia and increased lamina propria papillae were the significant specific finding for $\mathrm{EE}$ in esophageal biopsies. Esophageal dysmotility and occurrence of reflux were common and significant in patients with EE. Immuno-histochemistry had high sensitivity in detection of eosinophils and its degradation product in esophageal biopsies.

Conclusion: eosinophilic esophagitis is one of the causative factors of refractory GERD and its frequency is about $4 \%$.It should be put in differential diagnosis of cases of refractory GERD. Endoscopic picture is suggestive but biopsy for EE is confirmatory.

partially explained by the more diligent search for the disease or etiologyrelated changing mechanisms [4].

The prevalence of EE is highly variable and appears to depend on the characteristics of the study population. In a prospective studies indicated a low prevalence $(0.05-0.4 \%)$ in general population [5]. However, it may be up to $15 \%$ in patients with dysphagia [6] or as high as $48 \%$ in patients with food bolus impaction [7]. 
The clinical features of EE are not completely known due to the fact that few prospective studies have been conducted. However, EE is frequently associated with dysphagia, esophageal food impaction, allergic processes (aeroallergens, food, asthma) and some endoscopic abnormalities (concentric rings, longitudinal furrows, mucosal white plaques, strictures and narrowing of the esophageal lumen [8]. EE may also be associated with clinical symptoms suggestive of gastroesophageal reflux disease (GERD) such as heartburn and regurgitation in about $30 \%$ of cases [9]. Also cases with non-specific symptoms and normal endoscopy have been reported from $8 \%$ to $28 \%$ of cases [10].

For some time, the existence of a pathophysiological relationship between GERD and EE has been speculated, as eosinophilic infiltrates have been observed in the esophageal mucosa of patients with GERD. It has also been suggested that EE may cause secondary GERD [11]. Some authors have reported more than 20 eosinophils $\times$ HPF in patients with GERD, which disappeared after treatment with gastric acid inhibitors [12]. In other results it was observed that patients with $\mathrm{EE}$ are hypersensitive to acid perfused in the oesophagus, thus acid may play a role in the symptoms [11].

Although there may be overlapping of the two diseases, it is currently accepted that the EE is a pathological entity different from GERD, whose etiology seems to be related to allergic and genetic factors [13]. Consequently, EE symptoms respond well to topical steroid administration, while the response to gastric acid inhibitors is very limited.

We hypothesized that some patients with GERD symptoms who do not respond to conventional treatment may have EE. Currently this disease is not routinely considered in the differential diagnosis of refractory GERD. For this reason, we proposed as main objective to prospectively evaluate the frequency of $\mathrm{EE}$ in a consecutive population of patients with GERD who were refractory to conventional therapy, and as secondary objective to describe the clinical features and predictors of $\mathrm{EE}$ in this subset of patients.

The aim of this work is to estimate the frequency of eosinophilic esophagitis among patients with refractory reflux esophagitis, to study its effect on the course of the disease and to find in what way it can be differentiated from non refractory GERD.

\section{PATIENTS AND METHODS}

\section{Patients and study design :}

This study was done in Tropical Medicine and Pathology departments Faculty of Medicine Zagazig University, from July 2008 to December 2012. We prospectively studied patients who were treated at the outpatient clinic of the Gastroenterology Unit. We selected fifty patients diagnosed previously as refractory GERD as they had persistent esophageal or extra esophageal symptoms suggestive of GERD and are refractory to full dose PPI $(40 \mathrm{mg}$ ) treatment for 8 weeks (group I).Failure of response to 8 weeks treatment is taken as a base of refractory GERD according to Locke et al. [14]. Another fifty patients corresponding in age and sex with group I with esophageal and extra-esophageal clinical symptoms suggestive of non refractory GERD according to the GERD Symptoms Checklist were enrolled in this study as control (group II).

\section{Exclusion Criteria :}

We excluded patients diagnosed with :

1- Crohn's disease.

2- Scleroderma.

3- Fungal infections.

4- Collagen disease.

5- Esophageal carcinoma.

6- Drug induced esophagitis.

This study was performed on these patients to study the frequency and the role of eosinophilic infiltration on the course of GERD. All patients underwent a complete history taking included demographic data, history of environmental, food, and drug allergies, clinical symptoms suggestive of GERD, length of symptoms, type and duration of GERD treatment, adherence to treatment, and associated co-morbid states and diagnostic testing for GERD.

All patients are exposed to the following investigations :

1- CBC especially eosinophilic count.

2- Chemical laboratory tests including LFTs, KFTs and fasting blood sugar to exclude hepatic, renal and diabetes which affect esophageal motility.

3- Esophagogastroduodenoscopy: Using Pentax (EG-2940) endoscope to assess the presence of esophagitis, multiple biopsies were taken from the upper, middle and lower third of the esophagus. Esophageal biopsy specimens were obtained by direct endoscopic vision using fenestrated, ellipsoid, spiked $7 \mathrm{~mm}$ open 
span biopsy forceps. Four quadrant biopsies were taken from each subject essentially including areas suffer from sings of esophagitis.

Grading were done according to Los Angeles classification of esophagitis [15] :

\begin{tabular}{|c|l|}
\hline Grade A & $\begin{array}{l}\text { One (or more) mucosal break no longer than } 5 \mathrm{~mm} \text { that does not extend between the } \\
\text { tops of two mucosal folds }\end{array}$ \\
\hline Grade B & $\begin{array}{l}\text { One (or more) mucosal break more than } 5 \mathrm{~mm} \text { long that does not extend between the } \\
\text { tops of two mucosal folds }\end{array}$ \\
\hline Grade C & $\begin{array}{l}\text { One (or more) mucosal break that is continuous between the tops of two or more } \\
\text { mucosal folds but which involve less than } 75 \% \text { of the circumference }\end{array}$ \\
\hline Grade D & $\begin{array}{l}\text { One (or more) mucosal break which involves at least } 75 \% \text { of the esophageal } \\
\text { circumference }\end{array}$ \\
\hline
\end{tabular}

4- Oesophageal Manometry Study : We studied our cases using Sandhill Smart Lab. Computer Polygraph Manometry system.

Interpretation of the results :

1- Resting lower esophageal sphincter (LOS) Pressure : Two popular ways to measure the LOS pressure are from gastric baseline to the either mid-expiration or end-expiration pressure at the highest point. We used mid-expiration pressure because it provides a resting LOS pressure measurement that most reliably distinguishes patients with normal of gastrooesophageal reflux from those with abnormal amounts. Thus the pressure component contributed by the diaphragm during respiration may be an important component of the antireflux mechanism of the LOS and should be included in the assessment of overall resting pressure. We considered normal value of mid-expiration LOS pressure $24.4 \pm 10.1 \mathrm{mmHg}$ according to Ott et al. [16].
2- Oesophageal body motility : Measures are made for the peristaltic parameters: amplitude, and duration. Usually 10 wet swallows are assessed and parameters are based on the mean.

The values given below are considered to be standard for wet swallow [16]:

Normal oesophageal body pressure data :

\begin{tabular}{|c|c|}
\hline Wet swallows & Duration (sec) \\
\hline Amplitude (mmHg) & \\
$62 \pm 29$ & $2.8 \pm 0.8$ \\
$70 \pm 32$ & $3.5 \pm 0.7$ \\
$99 \pm 40$ & $3.9 \pm 0.9$ \\
\hline
\end{tabular}

5- Ambulatory Oesophageal Ph Monitoring Interpretation : Acid reflux was defined where the $\mathrm{PH}$ in the oesophagus dropped to 4.0 or less. In the analysis of oesophageal $\mathrm{PH}$ recording, different parameters were estimated including :

The variables advocated by Johnson and Demeester [17] :

\begin{tabular}{|c|c|}
\hline a- Parameter : Percent of time $\mathbf{p H}<\mathbf{4}$ & Normal value \\
\hline \% time reflux upright & $<6.3$ \\
$\%$ time reflux supine & $<1.2$ \\
$\%$ time reflux total & $<4.2$ \\
\hline b- Number of episodes: & $<50$ \\
\hline Total episodes & $<3$ \\
Episodes longer 5 min & $<9.2$ \\
Longest episode (min) & $<22$ \\
\hline c- Composite score & \\
\hline
\end{tabular}

6- Histological Examination : Diagnosis of EE is based on criteria described in diagnosis and treatment guidelines published in 2007. According to these guidelines, diagnosis is confirmed in patients with :
- Symptoms suggesting esophageal dysfunction, $-\geq 15$ eosinophils per HPF $(\times 400)$ in at least one esophageal biopsy samples, and

- Exclusion of other causes of esophageal eosinophilia [18]. 
Biopsy specimens were fixed in $4 \%$ formalin, embedded in paraffin, serially, sectioned and then stained with hematoxylin and eosin. Biopsy. Preparation and step serial sections of biopsy specimens were performed to enhance detection of eosinophils [19].

7- Immunohistochemistry : To detect eosinophilic count in oesophageal biopsies in both groups which refers to the process of detecting antigens of eosinophiles in tissue sections by exploiting the principle of antibodies binding specifically to antigens in biological tissues [20].

\section{RESULTS}

The mean, $\mathrm{SD}(\mathrm{X} \pm \mathrm{SD})$ and range of patients ages with refractory GERD (group I) were $37 \pm$ 14 and 20-70 years respectively. In addition $23(46 \%)$ were males and 27(54\%) were females. While the demographic data in patients with GERD (group II) show the mean , SD and range of ages were $32.9 \pm 13$ and 18-68 respectively in addition 24 (48\%) were males and 26 were females (52\%). There is no statistical significant difference in demographic data between the two groups.

The clinical picture of the studied patients showed that in group I heart burn, epigastric pain, vomiting, dysphagia, haematemsis and cough were $60 \%, 40 \%, 32 \%, 30 \%, 8 \%, 18 \%$ respectively while in group II they were $82 \%, 50 \%, 24 \%$, $14 \%, 22 \%$ and $20 \%$ respectively.There is statistical highly significant difference between the two groups only as regard heart burn.

The associated allergic diseases in the studied patients such as bronchial asthma, allergic rhinitis, allergic conjunctivitis and autoimmune diseases in group I were $10 \%, 10 \%, 4 \%$ and $8 \%$ while in group II were $12 \%, 4 \%, 4 \%$ and $2 \%$ respectively without statistical significant differences between both groups.

The endoscopic finding in the studied groups showed pathological changes as esophageal rings and furrows in 2 patients of group I (eosinophilic esophagitis patients).Los Angles classification showed that grade A,B,C and D were $50 \%, 26 \%$, $16 \%$ and $8 \%$ in group I while in group II were $82 \%$, $2 \%, 2 \%$ and $2 \%$ respectively. There was highly statistically significant difference between the two groups as regard endoscopic grading (table1).
The motility study in group I showed hypo peristalsis in 94\%, hyper peristalsis in $6 \%$ and hypotensive lower oesophageal sphincter(LES) in $92 \%$ while in group II were $70 \%$ hypo peristalsis, $30 \%$ hyper peristalsis and $80 \%$ hypotensive LES. There was highly significant difference between the two groups as regard the peristalsis but no significant statistical difference in the lower esophageal sphincter tone. 24- $\mathrm{pH}$ monitoring of group I showed that reflux state was present in $18 \%$ and absent in $82 \%$ of patients but in group II present in $86 \%$ and absent in $14 \%$. Reflux frequency were few in $10 \%$ and many in $90 \%$ in group I patients while was few in $68 \%$ and many in $32 \%$ in group II. There is highly statistical difference between both groups as regard the state of reflux (frequency and number of attacks).

There was no statistical significant difference between both groups as regard the count of blood eosinophils and esophageal biopsies eosinophils by histopathology. The eosinophilic count in the esophageal biopsies by immunohistochemistry revealed mean $\pm \mathrm{SD}$ of eosinophilic count in esophageal biopsies of group I was $2.72 \pm 4.6$ (range 0-27) while in group II were $0.76 \pm 1.5$ (range 0-5).There was highly significant difference between both groups (table 2). There was strong correlation between the eosinophilic count in esophageal biopsies by histopathology and immunohistochemistry $(r \geq .97, p<0.001)$.

The histopathological features in patients of EE patients (2 patients) showed the characters of EE; eosinophils $\geq 15 / \mathrm{HPF}$, increased lamina propria papillae in $100 \%$, basal zone hyperplasia in $50 \%$ and microabcess in 50\% while in other refractory GERD patients(48 patients) showed oedema in $58 \%$, neutrophils in $16 \%$, fibrosis in $4.8 \%$ and eosinophils $\leq 6$ cells /HPF in $6.3 \%$ with highly significant statistical difference between the two groups in microabcess, lamina propra papillae, oedema, basal zone hyperplasia, fibrosis and eosinophilic count and significant difference in neutrophils count (table 3 ).

Table (4) shows the histopatholigical findings of studied groups that reveal eosinophilic count (mean $\pm \mathrm{SD}$ ) in group I: $2.6 \pm 4.5$ (rang 0-27), lymphocyte not detected in $78 \%$ and detected in $22 \%$, microabcess in $4 \%$, fibrosis of lamina propria detected in $2 \%$ while leucocytes detected in $2 \%$ but group II showed eosinophilic count: 8 \pm 1.5 (range 0-5), lymphocyte, fibrosis, microabcess and leucocyte were not detected.There was highly significant difference between both groups as 
regard eosinphilic count and fibrocytes detected in the esophageal biopsies.

Table (1) : Upper GIT Endoscopy of studied patients (Los Angeles classification)

\begin{tabular}{|l|c|c|c|c|c|c|}
\hline \multirow{2}{*}{} & \multicolumn{2}{|c|}{ Group I } & \multicolumn{2}{c|}{ Group II } & \multirow{2}{*}{$\boldsymbol{X}^{2}$} & \multirow{2}{*}{ P } \\
\cline { 2 - 5 } & No & $\%$ & No & $\%$ & & \\
\hline Pathological finding & & & & & & \\
Rings & 2 & 4 & 0 & 0 & 2.04 & 0.15 (NS) \\
Furrows & 2 & 4 & 0 & 0 & 2.04 & 0.15 (NS) \\
Stricture & 2 & 4 & 0 & 0 & 2.04 & $0.15(\mathrm{NS})$ \\
Hiatus hernia & 10 & 20 & 41 & 82 & 2.99 & 0.08 (NS) \\
\hline Grade of GERD & & & & & & \\
A & 25 & 50.0 & 41 & 82.0 & 9.2 & $0.001^{*}(\mathrm{HS})$ \\
B & 13 & 26.0 & 1 & 2.0 & 8.9 & $0.004^{*}(\mathrm{HS})$ \\
C & 8 & 16.0 & 1 & 2.0 & 7.8 & $0.002^{*}(\mathrm{HS})$ \\
C & 4 & 8.0 & 1 & 2.0 & 12.9 & $0.004^{*}(\mathrm{HS})$ \\
\hline
\end{tabular}

Table (2) : Immunohistochemistry of esophageal biopsies of the studied patients

\begin{tabular}{|c|c|c|c|c|}
\hline & Group I & Group II & $\boldsymbol{X}^{2}$ & P \\
\hline $\begin{array}{c}\text { Eosinophils } \\
\mathrm{X} \pm \mathrm{SD} \\
\text { Range }\end{array}$ & $2.72 \pm 4.6$ & $0.76 \pm 1.5$ & & \\
\hline
\end{tabular}

Table (3) : Histopathological features in patients with EE and gastro-esophageal reflux

\begin{tabular}{|l|c|c|c|c|c|c|}
\hline & \multicolumn{2}{|c|}{$\begin{array}{c}\text { EE } \\
\text { patients } \\
\text { (N= 2) } \\
\text { Mean (range) }\end{array}$} & \multicolumn{2}{c|}{$\begin{array}{c}\text { Refractory } \\
\text { GERD } \\
\text { (N= 48) } \\
\text { Mean (range) }\end{array}$} & \multicolumn{2}{|l|}{} \\
\hline Eosinophil/HPF & \multicolumn{2}{|c|}{$20(12-25)$} & \multicolumn{2}{|c|}{$3(0-6)$} & & \\
\hline & No & \% & No & \% & $X^{2}$ & P \\
\hline Micoabcess & 1 & 50 & 0 & 0 & 9.4 & 0.001 (HS) \\
Increasea lamina propra papillae & 2 & 100 & 3 & 6.3 & 12.1 & $0.003(\mathrm{HS})$ \\
Basal zone hyperplasia & 1 & 50 & 4 & 8.3 & 8.1 & 0.004 (HS) \\
Oedema & 0 & 0 & 28 & 58.3 & 7.6 & 0.004 (HS) \\
Neutophils & 0 & 0 & 8 & 16.6 & 5.4 & 0.03 (SD) \\
Eosinophils & 2 & 100 & 3 & 6.3 & 10.4 & $0.001(\mathrm{HS})$ \\
Fibrosis & 1 & 50 & 2 & 4.8 & 6.7 & 0.003 (HS) \\
\hline
\end{tabular}


Table (4) : Histopathology of studied groups

\begin{tabular}{|c|c|c|c|c|c|c|}
\hline & \multicolumn{2}{|c|}{ Group I } & \multicolumn{2}{|c|}{ Group II } & \multirow{2}{*}{$X^{2}$} & \multirow{2}{*}{$\mathbf{P}$} \\
\hline & No & $\%$ & No & $\%$ & & \\
\hline $\begin{array}{c}\text { Eosinophil count } \\
X \pm S D \\
\text { Range }\end{array}$ & \multicolumn{2}{|c|}{$\begin{array}{c}2.6 \pm 4.5 \\
0-27 \\
\end{array}$} & \multicolumn{2}{|c|}{$\begin{array}{c}0.8 \pm 1.5 \\
0-5 \\
\end{array}$} & 8.6 & $0.003 *(\mathrm{HS})$ \\
\hline $\begin{array}{c}\text { Lymphocytes } \\
\text { Not detected } \\
\text { Detected }\end{array}$ & $\begin{array}{l}39 \\
11\end{array}$ & $\begin{array}{l}78.0 \\
22.0\end{array}$ & $\begin{array}{c}50 \\
0\end{array}$ & $\begin{array}{c}100.0 \\
0.0\end{array}$ & 12.36 & $0.001 *(\mathrm{HS})$ \\
\hline $\begin{array}{l}\text { Leucocytes } \\
\text { Not detected } \\
\text { Detected } \\
\end{array}$ & $\begin{array}{c}48 \\
2 \\
\end{array}$ & $\begin{array}{c}96.0 \\
4.0 \\
\end{array}$ & $\begin{array}{c}50 \\
0 \\
\end{array}$ & $\begin{array}{c}100.0 \\
0.0 \\
\end{array}$ & 2.04 & $\begin{array}{l}0.15 \\
(\mathrm{NS}) \\
\end{array}$ \\
\hline $\begin{array}{c}\text { Microabscess } \\
\text { Not detected } \\
\text { Detected }\end{array}$ & $\begin{array}{c}48 \\
2\end{array}$ & $\begin{array}{c}96.0 \\
4.0\end{array}$ & $\begin{array}{c}50 \\
0\end{array}$ & $\begin{array}{c}100.0 \\
0.0\end{array}$ & 2.04 & $\begin{array}{l}0.15 \\
(\mathrm{NS})\end{array}$ \\
\hline $\begin{array}{c}\text { Fibrosis lamina pro. } \\
\text { Not detected } \\
\text { Detected }\end{array}$ & $\begin{array}{c}48 \\
2 \\
\end{array}$ & $\begin{array}{c}96.0 \\
4.0\end{array}$ & $\begin{array}{c}50 \\
0\end{array}$ & $\begin{array}{c}100.0 \\
0.0\end{array}$ & 2.04 & $\begin{array}{l}0.15 \\
(\mathrm{NS})\end{array}$ \\
\hline
\end{tabular}

\section{DISCUSSION}

Although we had known that eosinophilic esophagitis (EE) prevalence is low among the population, this study was conducted to through the light towards this disease.

One hundred patients were enrolled in this study, 50 patients with refractory GERD (group I) and the other with non refractory GERD (group II). All patients were studied clinically, endoscopically, manometerically and histopathologically to evaluate the presence of eosinophilic infiltration and its role in refractory esophageal pathology.

The demographic data of this study showed no statistical significant difference among the patients sex of two groups, with GERD either with or without refractory entity. This finding is in agreement with Vindigni et al. [21] but in contrary with Forountan et al. [22] who mentioned that the disease show female predominance. This difference can be explained by age and parity difference. The same findings of non-statistical significant difference were founded as regarding the age. This is consistent with Dellon et al. [23], but in contrary with Liacouras et al. [24] who mentioned that refractory GERD was more predominant in old ages. This can be explained by the effect of aging on the LES tone [25].

The clinical picture showed no statistical significant difference between both groups as regard dysphagia, vomiting, haematemsis, itching, cough, pallor, wheezes and urticaria, but there is a statistical significant difference as regard heart burn. These results were in agreement with Molina-Infante et al. [26], and not in agreement with Aceves et al. [27] who mentioned that the dysphagia is the most common presenting symptoms in patients with refractory GERD. This difference can be explained by variability in the duration of disease. Where Richter [28] reported that the more advanced pathological findings were encountered in patients with long history of disease, as they selected their patients with long history of GERD.

The associated disease as allergic rhinitis, allergic conjunctivitis, bronchial asthma and auto immune diseases showed no statistical significant difference between the studied groups and these results were in agreement with Martinez et al. [29], but in contrary with Liacouras et al. [24] who stated that $28 \%$ of their patients suffer from associated allergic disease and this can be explained by relative low rate of allergic diseases in both groups of patients in this study.

The endoscopic finding in the studied groups showed pathological changes as esophageal rings and furrow in eosinophilic esophagitis patients (2 patients) and this was in agreement with Venge et al. [30] but in contrary with Remedios et al. [9] who stated that, plaques were the most common endoscopic findings in their patients but none was diagnosed with a ringed esophagus which is one of the most typical findings in the previous studies, together with linear furrows. This difference can be explained by seasonal variation and multiple variety in the endoscopic picture of EE [31]. There was a statistically significant difference between the two groups as regard endoscopic grading of esophagitis. These result 
was in agreement with Dellon et al. [23], but in contrary with Shah et al. [32] who stated that no endscopic difference among their studied groups. This variation can be explained by difference in operator experience, prevalence of EE and treatment used before endscopy. The more pathological changes may be attributed to the events which reported by Hirano [33] as prolonged exposure of esophageal mucosa to acid, partial response of EE to PPI therapy and toxic effect of eosinophilic degranulation into the tissue.

The motility study of both groups showed highly statistical significant difference between the two groups as regard the peristalsis but no statistical difference in the lower esophageal sphincter tone. These result were in agreement with Pandolfino et al. [34] but in contrary with Tian et al. [35] and this difference can be explained by finding of Mueller et al. [36] as variations in factors controlling esophageal peristalsis and lower esophageal sphincter such as diet, hormonal, nervous, drugs and eosinophilic granule constituents which are toxic to a variety of tissues, including esophageal epithelium. Study of 24-ph monitoring of patients group shows a significant statistical difference between both groups as regard the state of reflux(frequency and number of attacks).These result in agreement with Weusten et al. [37], but differ with Mattioli et al. [38] who stated that $25 \%$ of GERD with esophagitis have $24 \mathrm{~h} \mathrm{pH}$ monitoring within normal range. This variation can be explained by difference in defensive factories such as LES and luminal clearance of acids [39] or variation of injurious factors such as prolonged transient esophageal sphincter relaxation, hiatus hernia and blood supply [40].

As regard the eosinophilic count in peripheral blood which showed no statistical significant difference between patients of both groups and this finding is in agreement with Gonsalves et al. [41]. It is known that $\mathrm{EE}$ is a chronic immunoallergic disorder characterized by clinical symptoms related to esophageal dysfunction and eosinophilic infiltration in the esophagus regardless the peripheral blood eosinophilic count [42]. The relation between peripheral blood eosinophils and esophageal biopsies eosinophilis showed no statistical significant difference. This result was in agreement with Attwood et al. [25], however, the result of this study was differing with Brown et al. [43]. This variation can be explained by more advances in diagnostic tools and nowadays $\mathrm{EE}$ is considered a local allergy of esophagus to foods (asthma of esophagus) [44]. Regarding to the eosinophilic count in the esophageal biopsies by immuno-histochemistry revealed a statistical significant difference between both groups. These result was in agreement with Leader et al. [45]. Study of esophageal eosinophilia by H\&E and immune histochemistry showed highly statistical significant difference between eosinophilic count by H\&E stain and immunohistochemistry stain. This result was in agreement with Mueller et al. [36] who stated that the immunohistochemistry detected up to two times more eosinophils than routine haematoxylin and eosin staining and can perhaps be used to discover minimal change EE. We did not find any study differ with this result as eosinophils morphologically are easily to see in conventional histology. Moreover, it is almost impossible to identify degranulated eosinophils with haematoxylin and eosin staining [46].

Correlation between eosinophilic count in esophageal biopsies by histopathology and immune histochemistry showed highly statistical significant correlation. This results were in agreement with Onbasi et al, [47] who reported that immune histochemistry using monoclonal anti body is the most sensitive method for eosinohils detection.

The histopatholigical finding in group I that showed a highly statistical significant difference between the 2 EE patients and other 47 refractory GERD patients as regard eosinphilic count, fibrocytes, oedema, basal cell hyperplasia and fibrosis detected in the esophageal biopsies these finding were in agreement with Spergel et al. [48] who founded that eosinoplic infiltration of esophageal mucosa $\geq 15$ cells/hpf, oedema, basal cell hyperplasia and fibrosis are charachterstic of EE.

The histopathological finding in both groups showed highly statistical significant differences in tissue eosinophilic count and lymphocyte but no statistical differences in leucocyte, microabcess and fibrosis lamina propria. These were in agreement with Straumann et al. [49]. The cause of eosinophilic infiltration is poorly understood, but allergy has been implicated. The majority of patients have evidence of food and aeroallergen hypersensitivity, as defined by skin prick test responses, however, only a minority have a history of food anaphylaxis [50], this indicating distinct mechanisms compared with classical IgE-mediated mast cell/basophil activation. Substantial evidence is accumulating that EE is associated with TH2-type immune responses. In 
particular, increased levels of eosinophil-active TH2 cytokines (eg, IL-4, IL-5, and IL-13), as well as mast cells, are present in the esophagi of patients with EE [51].

\section{CONCLUSION}

Finally it can be concluded that the eosinophilic esophagitis is one of the causative factors of refractory GERD and its frequency is about $4 \%$.It should be put in differential diagnosis of cases of refractory GERD. Endoscopic picture is suggestive but biopsy for EE is confirmatory. $\mathrm{H} \& \mathrm{E}$ stain appearance is cost-effective approach for diagnosis.

\section{Funding: Non.}

Conflicts of interest: The authors declare no conflict of interest.

Ethical approval: The study was approved by the Ethical Committee of Zagazig Faculty of Medicine and a written informed consent was taken from each participant that follows principles in the Declaration of Helsinki.

\section{REFERENCES}

1. Yan BM, Shafer EA. Eosinophilic esophagitis. A newly established cause of disphagia. World $J$ Gastroneterol 2006; 12: 2328-2334.

2. Sgouros SN, Bergele C, Mantides A. Eosinophilic esophagitis in adults: a systematic review. Eur $J$ Gastroenterol Hepatol 2008; 18: 211-217.

3. Moawad FJ, Veerappan GR, Wong RK. Eosinophilic esophagitis. Dig Dis Sci 2009; 54: 1818-1828.

4. Prasad GA, Alexander JA, Schleck CD. Epidemiology of eosinophilic esophagitis over three decades in Olmsted Country, Minnesota. Clin Gastroenterol Hepatol 2009; 7: 1055-1061.

5. Ronkainen J, Talley NJ, Aro P. Prevalence of eosinophilia and eosinophilic esophagitis in adults in the community: a random population based study. Gastroenterology 2007; 130, A575.

6. Mackenzie SH, Go M, Chadwick B. Eosinophilic oesophagitis in patients presenting with dysphagia - a prospective analysis. Aliment Pharmacol Ther 2008; 28: 1140-1146.

7. Kerlin P, Jones D, Remedios M, Campbell C. Prevalence of eosinophilic esophagitis in adults with food bolus obstruction of the esophagus. $J$ Clin Gastroenterol. 2007 Apr; 41(4):356-61.

8. Müller S, Pühl S, Vieth M. Analysis of symptoms and endoscopic findings in 117 patients with histological diagnoses of eosinophilic esophagitis. Endoscopy 2007; 39: 339-344.
9. Remedios M, Campbell C, Jones DM. Eosinophilic esophagitis in adults: clinical, endoscopic, histologic findings, and response to treatment with fluticasone propionate. Gastrointest Endosc 2006; 63: 3-12.

10.Sgouros SN, Bergele C, Mantides A. Eosinophilic esophagitis in adults: a systematic review. Eur J Gastroenterol Hepatol 2006; 18: 211-217.

11. Krarup AL, Villadsen GE, Mejlgaard E. Acid hypersensitivity in patients with eosinophilic oesophagitis. Scand J Gastroenterol 2010; 45:273281.

12. Ngo P, Furuta GT, Antonioli DA. Eosinophils in the esophagus: peptic or allergic eosinophilic esophagitis? Case series of three patients with esophageal eosinophilia. Am J Gastroenterol 2006; 101: 1666-1670.

13. Penfield JD, Lang DM, Goldblum JR. The role of allergy evaluation in adults with eosinophilic esophagitis. J Clin Gastroenterol 2010; 44: 22-27.

14. Locke GR, Talley NJ, Weaver AL. A new questionnaire for gastroesophageal reflux disease. Mayo Clin Proc 1994; 69: 539-547.

15. Lundell LR, Dent J, Bennett JR. Endoscopic assessment of oesophagitis: clinical and functional correlates and further validation of the Los Angeles classification. Gut 1999; 45: 172-180.

16. Ott DJ, Joel ER, Yu MS. Esophageal radiology and manometry correlation in 187 patients with dysphagia. A.J.R 1987; 149:307-3011.

17. Johnsom L, De.,Meester. Tewenty four hour ph monitoring of the distal oesphagus.Am.J Gastroentrology 1974;62:322-325.

18. Furuta GT, Liacouras CA, Collins MH. Eosinonophilic esophagitis in children and adults: a systematic review and consensus recommendations for diagnosis and treatment. Gastroenterology 2007; 133: 1342 1363.

19. Haggitt R.C., Rubin. Adenocarcinoma in Barrett's oesophagus:a new epidemic?. Human pathology 1992; 23:475-276.

20. Ramos-Vara. "Technical Aspects of Immunohistochemistry". Vet Pathol 2005;42 (4): 405-426.

21. Vindigni C, Villanacci V, Marini M. Eosinophilic esophagitis: an Italian experience. Rev Esp Enferm Dig 2010; 102 (1): 15-19.

22. Foroutan M, Norouzi A, Molaei M. Eosinophilic esophagitis in patients with refractory gastroesophageal reflux disease. Dig Dis Sci 2010; 55 (1): $28-31$.

23. Dellon ES, Aderoju A, Woosley JT. Variability in diagnostic criteria for eosinophilic esophagitis: a systematic review. Am J Gastroenterology 2007; 184: 14-18. 
24. Liacouras CA, Spergel JM, Ruchelli E. Eosinophilic esophagitis: a 10-year experience in 381 children. Clin Gastroenterol Hepatol 2005; 3: 1198-1206.

25. Attwood SE, Smyrk TC, Demeester TR. Esophageal eosinophilia with dysphagia. A distinct clinicopathologic syndrome. Dig Dis Sci 1993; 38:109-116.

26. Molina-Infante J, Ferrando-Lamana L, Ripoll C. Esophageal eosinophilic infiltration responds to proton pump inhibition in most adults. Clin Gastroenterol 2011; 9: 110-117.

27. Aceves SS, Newbury RO, Chen D. Resolution of remodeling in eosinophilic esophagitis correlates with epithelial response to topical corticosteroids. Allergy 2010; 65 (1): 109-116.

28. Richter J.E. Peptic stricture of the esophagus Gastroenterology. Clinics of North America 1999; 31: 875-891.

29. Martinez SD, Malagon IB, Garewal HS, Cui H, Fass R. Non-erosive reflux disease (NERD)-acid reflux and symptom patterns. Aliment Pharmacol Ther 2003; 15; 17(4):537-45.

30. Venge P, Byström J, Carlson M, Hâkansson L, Karawacjzyk M, Peterson $\mathrm{C}$ et al. Eosinophil cationic protein (ECP): molecular and biological properties and the use of ECP as a marker of eosinophil activation in disease. Clin Exp Allergy 1999; 29(9):1172-86.

31. Rodrigo S, Abboud G, Oh D, DeMeester SR, Hagen J, Lipham J, DeMeester TR, Chandrasoma P. High intraepithelial eosinophil counts in esophageal squamous epithelium are not specific for eosinophilic esophagitis in adults. Am J Gastroenterol 2008; 103(2):435-42.

32. Shah A, Kagalwalla AF, Gonsalves N, MelinAldana H, Li BU, Hirano I. Histopathologic variability in children with eosinophilic esophagitis. Am J Gastroenterol 2009; 104(3):716-21

33. Hirano I. Eosinophilic esophagitis and gastroesophageal reflux disease: there and back again. Clin Gastroenterol Hepatol 2011; 9(2):99-101.

34. Pandolfino JE, Bianchi LK, Lee TJ, Hirano I, Kahrilas PJ. Esophagogastric junction morphology predicts susceptibility to exercise-induced reflux. Am J Gastroenterol 2004; 99(8):1430-6.

35. Tian ZQ, Liu JF, Wang GY, Li BQ, Wang FS, Wang QZ, Cao FM, Zhang YF. Responses of human clasp and sling fibers to neuromimetics. $J$ Gastroenterol Hepatol 2004; 19(4):440-7.

36. Mueller S, Aigner T, Neureiter D, Stolte M. Eosinophil infiltration and degranulation in oesophageal mucosa from adult patients with eosinophilic oesophagitis: a retrospective and comparative study on pathological biopsy. J Clin Pathol 2006; 59(11):1175-80.
37. Weusten BL, Roelofs JM, Akkermans LM, Van Berge-Henegouwen GP, Smout AJ. The symptomassociation probability: an improved method for symptom analysis of 24-hour esophageal $\mathrm{pH}$ data. Gastroenterologl 1994; 107(6):1741-5.

38. Mattioli S, Pilotti V, Spangaro M, Grigioni WF, Zannoli R, Felice V, Conci A, Gozzetti G. Reliability of 24-hour home esophageal $\mathrm{pH}$ monitoring in diagnosis of gastroesophageal reflux. Dig Dis Sci 1989; 34(1):71-8.

39. Orlando RC. Reflux esophagitis. In: YamadaT, Alpers DH, OwyangC, PowellDW, SilversteinFE, eds. Textbook of Gastroenterology. Philadelphia: JB Lippincott 1999; 1123.

40. Tobey NA, Hosseini SS, Caymaz-Bor C, Wyatt HR, Orlando GS, Orlando RC. The role of pepsin in acid injury to esophageal epithelium. $A m J$ Gastroenterol 2001; 96(11):3062-70.

41. Gonsalves N, Policarpio-Nicolas M, Zhang Q, Rao MS, Hirano I. Histopathologic variability and endoscopic correlates in adults with eosinophilic esophagitis. Gastrointest Endosc. 2006; 64(3):313-9.

42. Franciosi JP, Hommel KA, Bendo CB, King EC, Collins MH, Eby MD et al. PedsQL eosinophilic esophagitis module: feasibility, reliability, and validity. J Pediatr Gastroenterol Nutr 2013; 57(1): 57-66.

43. Brown LF, Goldman H, Antonioli DA. Intraepithelial eosinophils in endoscopic biopsies of adults with reflux esophagitis. Am J Surg Pathol 1984; 8(12): 899-905.

44. Rothenberg ME, Mishra A, Brandt EB, Hogan SP. Gastrointestinal eosinophils in health and disease. Adv Immunol 2001;78:291-328.

45. Leader M, Patel J, Makin C, Henry K. An analysis of the sensitivity and specificity of the cytokeratin marker CAM 5.2 for epithelial tumours. Results of a study of 203 sarcomas, 50 carcinomas and 28 malignant melanomas. Histopathology 1986 ;10(12):1315-24.

46. Levy AM, Yamazaki K, Van Keulen VP, Burgart LJ, Sandborn WJ, Phillips SF et al. Increased eosinophil infiltration and degranulation in colonic tissue from patients with collagenous colitis. Am J Gastroenterol 2001 ;96(5):1522-8.

47. Onbasi K, Sin AZ, Doganavsargil B, Onder GF, Bor S, Sebik F. Eosinophil infiltration of the oesophageal mucosa in patients with pollen allergy during the season. Clin Exp Allergy 2005; 35(11): 1423-31.

48. Spergel JM, Beausoleil JL, Mascarenhas M, Liacouras CA. The use of skin prick tests and patch tests to identify causative foods in eosinophilic esophagitis. J Allergy Clin Immunol 2002; 109(2): 363-8. 
49. Straumann A, Bauer M, Fischer B, Blaser K, Simon HU. Idiopathic eosinophilic esophagitis is associated with a $\mathrm{T}(\mathrm{H}) 2$-type allergic inflammatory response. J Allergy Clin Immunol 2001; 108(6): 954-61.

50. Fox VL, Nurko S, Furuta GT. Eosinophilic esophagitis: it's not just kid's stuff. Gastrointest Endosc 2002; 56(2):260-70.

51. Blanchard C, Wang N, Stringer KF, Mishra A, Fulkerson PC, Abonia JP et al. Eotaxin-3 and a uniquely conserved gene-expression profile in eosinophilic esophagitis. J Clin Invest 2006; 116(2):536-4.

Peer reviewer:Mostafa Elshami ;Professor of Tropical Medicine and Hepatogastroenterology,Faculty of Medicine , Zagazig University, Egypt.Editor:Mohamad Emara; Lecturer of Tropical Medicine and Hepatogastroenterology, Faculty of Medicine , Zagazig University, Egypt. 